\title{
Prevalence, factors associated and treatment outcome of hyperbilirubinaemia in neonates admitted to St Francis hospital, Nsambya, Uganda: a descriptive study
}

\author{
Catherine Nyangabyaki-Twesigye ${ }^{1}$, Edison Mworozi ${ }^{2}$, Charles Namisi ${ }^{3}$, Victoria Nakibuuka ${ }^{1}$, \\ Joshua Kayiwa ${ }^{4}$, Robert Ssebunya ${ }^{1}$, David Aggrey Mukose ${ }^{5}$
}

1. Nsambya Hospital, Kampala, Uganda, Paediatrics and Child Health.

2. Mulago hospital, Paediatrics and Child Health; College Of HealthSciences Makerere University, Paediatrics\&Child Health.

3. Makerere University; Ugandan Academy for Health Impact and Innovation, Infectious Disease Institute, College of Health Sciences, Makerere University, P.O. Box 22418, Kampala. Department of Epidemiology and Biostatistics, School of Public Health.

4. Republic of Uganda Ministry of Health, Public Health Emergency Operations Centre.

5. Makerere University, Department of Epidemiology and Biostatistics, School of Public Health.

\begin{abstract}
Background: With targeted management of neonatal hyperbilirubinaemia in high-income countries, there has been a drastic drop in both the prevalence and mortality. On the contrary, over two-thirds of the global burden of neonatal hyperbilirubinaemia is in Sub-saharan Africa and South East Asia with a high mortality risk of 16-35\%. Neonatal hyperbilirubinaemia is not a leading global cause of neonatal mortality, however leads to irreversible neurological damage and death when managed poorly. Three-quarters of the babies admitted to the national referral hospital in Uganda had significant hyperbilirubinaremia; $16.6 \%$ of these babies died. We aimed at determining the prevalence, treatment outcome and describing factors associated with hyperbilirubinaemia in neonates admitted to St Francis hospital, Nsambya.

Methods: A cross sectional study was carried out. A total of 242 files of babies with a preliminary diagnosis of hyperbilirubinaemia were retrieved retrospectively. Relevant data was extracted from the files and analysed using STATA version 14.0.

Results: The prevalence of significant hyperbillirubinaemia was $22.7 \%(55 / 242)$. Seventy-seven percent of the babies admitted did not require treatment for hyperbilirubinaemia. No factors were found to be significantly associated with significant hyperbilirubinaemia. The case fatality for severe hyperbilirubinaemia was $20 \%(6 / 30)$; half of these babies had haemolytic disease of the newborn.

Conclusion: Establishment of local guidelines will prevent unnecessary admissions and ensure timely treatment is administered. Longitudinal studies are required to discover factors associated with neonatal hyperbilirubinaemia in this region.

Keywords: neonatal jaundice, hyperbilirubinaemia, phototherapy, exchange transfusion.

DOI: https://dx.doi.org/10.4314/ahs.v20i1.46

Cite as: Nyangabyaki-Twesigye C, Mworozi E, Namisi C, Nakibunka V, Kayiwa J, Ssebunya R, Mukose DA. Prevalence, factors associated and treatment outcome of hyperbilirubinaemia in neonates admitted to St Francis hospital, Nsambya, Uganda: a descriptive study. Afri Health Sci. 2020;20(1):397-405. https:/ / dx.doi.org/10.4314/abs.v20i1.46
\end{abstract}

\section{Introduction}

Over the last 25 years there has been a global reduction in the under- 5 mortality rate by $52 \%$, however the drop in neonatal mortality has been by only $42 \%,{ }^{1}$.

Neonatal deaths represented $45.1 \%$ of all under-5

\section{Corresponding author:}

Catherine Nyangabyaki-Twesigye,

Nsambya Hospital, Kampala, Uganda,

Paediatrics and Child Health.

Email: cadyerin@gmail.com deaths globally in 2015, the commonest causes being birth asphyxia, prematurity and sepsis ${ }^{2}$. Neonatal hyperbilirubinaemia was estimated to cause approximately 8/100,000 of all under-5 deaths worldwide in $2016^{3}$. Sub-Saharan Africa and South East Asia contribute $70 \%$ of the global cases of severe neonatal hyperbilirubinaemia annually with a mortality risk of $16-35 \%{ }^{4}$.

Neonatal hyperbilirubinaemia is mostly benign, but a few babies will develop severe disease (severe hyperbilirubinaemia) leading to long term neurological disabilities and/ or death. Research carried out in high-income 
countries (HICs) to ascertain risk factors for severe disease has led to the development of guidelines and a large drop in neonatal hyperbilirubinaemia-associated complications and mortality ${ }^{5}$. However, in many low and middle income countries (LMICs) hyperbilirubinaemia is not identified as a cause of serious morbidity and mortality both by health workers and caretakers ${ }^{4}$. Thus, very few LMICs have established or adapted guidelines to help manage these babies appropriately ${ }^{5}$. Maternal factors that have been associated with severe disease include age $>25$ years, race (e.g. African Americans and Orientals), history of jaundice in another family member and vacuum delivery ${ }^{6}$. Neonatal risk factors include breastfeeding at discharge following delivery in a hospital, low birth weight and male $\operatorname{sex}^{6}$. A Nigerian study showed that babies referred to a hospital for treatment(having been born elsewhere/being outborn) and a low socioeconomic status were associated with a higher chance of developing severe disease, with the outborn being about 10 times more at risk ${ }^{7}$. Excessive weight loss and sepsis ${ }^{8}$ have also been associated with severe hyperbilirubinaemia.

In Nigeria, Glucose-6-Phosphate Dehydrogenase (G6PD) deficiency was as high as $31 \%$ in babies ${ }^{9}$ who presented to a private hospital with hyperbilirubinaemia. An Indian study showed babies with $\mathrm{ABO}$ incompatibility were 2.6 times more likely to develop hyperbilirubinaemia ${ }^{10}$ and $41.7 \%$ of babies with severe hyperbilirubinaemia in a South African study had ABO incompatibility ${ }^{11}$.

There is paucity of data on neonatal hyperbilirubinaemia in Uganda. A follow-up study carried out in 2009 at Mulago national referral hospital (unpublished data), revealed that $42 / 200(21 \%)$ of the neonates admitted to the special care baby unit for various reasons developed neonatal hyperbilirubinaemia. More than three quarters $(33 / 42)$ of these babies had significant jaundice and $16.6 \%$ of these babies died ${ }^{12}$.

The annual analytic report for St. Francis hospital, Nsambya for 2013 showed that neonatal jaundice was the 5 th commonest cause of admission to the baby unit. Neonatal jaundice and its complications accounted for $6 \%$ of the deaths in the unit (unpublished report).

Globally, neonatal hyperbilirubinaemia is not among the commonest causes of neonatal mortality. However, when not managed appropriately and promptly it leads to long term neurological damage and death. Discovering the burden of disease, identifying the risk factors and gaps in the management of hyperbilirubinaemia in our population will enable us manage it better. This study therefore aimed at looking at the prevalence, treatment outcome and factors associated with hyperbilirubinaemia in neonates admitted to the baby unit.

\section{Methods}

\section{Study setting, design and eligible criteria}

The study was conducted among neonates admitted to St Camillus baby unit at St Francis hospital, Nsambya. St Francis hospital, Nsambya is located within Kampala, the capital city of Uganda. It is a private, not for profit Catholic-based hospital and a teaching hospital for Mother Kevin postgraduate medical school of Uganda Martyr's University. The newborn unit receives between 170-240 high risk babies per month from labour wards within the hospital and surrounding health facilities. During the study period 4840 babies were admitted to the Baby unit.

The study was a cross sectional retrospective chart review. Files of babies admitted with a preliminary diagnosis of hyperbilirubinaemia in the 2 year period between July 2012 and June 2014 were retrieved. Neonates with a direct serum bilirubin level greater than $20 \%$ of their total serum bilirubin level (TSB) were excluded from the study. These babies were excluded because their mode of management is different.

Sample size determination and selection of patients We used the Kish Leslie (1965) formula ${ }^{13}$ for sample size computations of cross-sectional study designs. Overall, a total number of 375 neonates were admitted during this study period with a preliminary diagnosis of hyperbilirubinaemia. We however lacked data in the Ugandan settings documenting prevalence of neonatal hyperbilirubinaemia and thus adopted the prevalence of $35 \%$ which was documented in a study from Nige$\mathrm{ria}^{14}$. In the computation, we set the alpha level at $99 \%$, which would allow us assess prevalence with a $1 \%$ level of error. We further aimed at allowing for an attrition rate of $4 \%$ to cater for chart reviews with missing or insufficient information. Using these parameters, we computed a sample size of 242 babies with a unit design effect.

During this study period, all babies that came to the Paediatric outpatient clinic and had visible yellow discolouration of the skin or/and sclera had a TSB done. The protocol being used was that any neonate with a TSB $\geq 20 \mathrm{mg} / \mathrm{dl}$ or assessed by the attending doctor as having signs of neurological involvement (observed as poor feedingconvulsions or abnormal posturing) at a 
TSB of $<20 \mathrm{mg} / \mathrm{dl}$ was admitted and managed with an exchange transfusion. Decision as to whether to admit a baby with a TSB $<20 \mathrm{mg} / \mathrm{dl}$ with no signs of neurological involvement was at the discretion of the attending doctor. Very often, however, the unavailability of appropriate blood for exchange transfusion would lead to suboptimal management with a single lullaby LED phototherapy unit or fluorescent phototherapy units. All other babies with hyperbilirubinaemia were treated with a Fluorescent (Contrex Medical st A20) phototherapy unit or locally made Fluorescent phototherapy units. Fluorescent blue or white light tubes were used and changed when they would stop functioning.

\section{Study measurements}

The primary study outcome was the severity of hyperbilirubinaemia. The secondary study outcome measure was the treatment given and the status at discharge; either alive or dead.

\section{Analysis}

Relevant data was extracted from the files and entered into a pre-designed questionnaire. This information was entered in a computer using Epi-Data version 3.1 and with the help of a statistician was cleaned and analysed using STATA version 14.0. For analysis, the babies were grouped according to their age on admission (in hours) and whether they were term or preterm (less than 37 weeks of gestation was considered preterm). The American Academy of Paediatrics guidelines (AAP) for neonates with low risk (those $>38 / 40$ gestational age and well) was used for term babies and medium risk (those 35-37/40 and well) was used for preterm babies to identify which babies required exchange transfusion and which required intensive phototherapy. The graphs for babies with high risk were not used since the risk factors of sepsis, birth asphyxia, e.t.c were not reported in most of the files. The AAP guidelines were used be- cause of the absence of comprehensive guidelines for the management of neonatal hyperbilirubinaemia in the country. The guideline at the hospital at the time of the study was only for those that required exchange transfusion.

For this study, severe hyperbilirubinaemia was defined as the TSB at which babies should receive exchange transfusion (in accordance to the AAP guidelines). Significant hyperbilirubinaemia was defined as the TSB levels at which a baby should receive treatment-either intensive phototherapy or exchange transfusion-in accordance to the AAP guidelines.Continuous data that was normally distributed was summarised as means and standard deviations and appropriate tests applied to skewed data. Bivariate and multivariate analyses using logistic regression were used to identify factors associated with significant hyperbilirubinaemia. All factors that were analysed at bivariate level were considered for multivariate analysis because literature showed that they were found to be associated with severe hyperbilirubinaemia.

\section{Ethical considerations}

Waiver of consent was obtained from the Research and Ethics Committee of St Francis hospital, Nsambya.

\section{Results}

Only $17 / 242(7.0 \%)$ of the babies were born preterm (median age of 34 weeks IQR 30, 35 weeks), whereas the remaining 225/242 (93.0\%)) were term babies.

At admission, all the babies were below 30 days of age. Specifically, $6 / 242(2.5 \%)$ babies were aged $\leq 24.0$ hrs; $26 / 242(10.7 \%)$ were aged $24.1-48.0$ hrs; $49 / 242$ $(20.3 \%)$ were aged $48.1-72.0 \mathrm{hrs} ; 28 / 242(11.6 \%)$ were aged $72.1-96.0 \mathrm{hrs}$ and 133/242 (66.5\%) were $\geq 96.1$ hrs old.

See Study profile of study participants, Figure_1. 


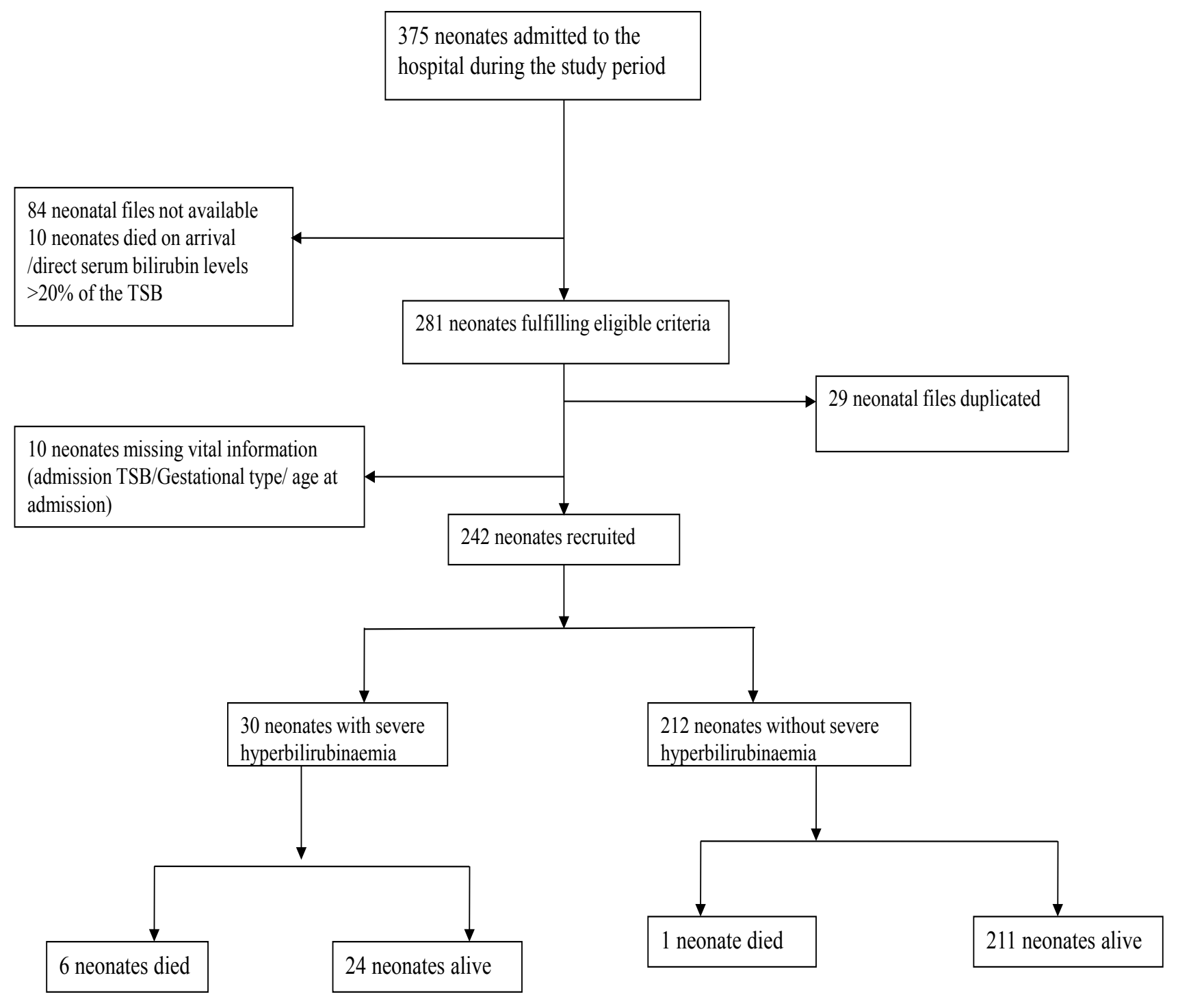

Figure 1: Study profile of the patients

The mean TSB at admission for babies with severe hyperbilirubinaemia was $31.9 \pm \mathrm{SD} 6.7 \mathrm{mg} / \mathrm{dl}$ and for significant hyperbilirubinaemia, was $25.8 \pm$ SD $8.6 \mathrm{mg} /$ dl. The mean TSB of babies who did not require any treatment was $13.7 \pm$ SD $3.6 \mathrm{mg} / \mathrm{dl}$.
At the time of discharge, the mean TSB of babies with significant hyperbilirubinaemia and those not requiring treatment was comparable, being $12.6 \pm 4.2 \mathrm{mg} / \mathrm{dl}$ and $11.4 \pm \mathrm{SD} 2.4 \mathrm{mg} / \mathrm{dl}$ respectively.

The socio-demographic factors of the baby and mother are as in Table 1. 
Table 1: Socio-demographic characteristics of study participants

\begin{tabular}{lll}
\hline Variable (n)* & Total in category & Percentage \\
\hline Maternal age (222) & & \\
16-24 years & 66 & $29.7 \%$ \\
$\geq 25$ years & 156 & $71.3 \%$ \\
Parity (234) & & \\
1 & 108 & $46.2 \%$ \\
$\geq 2$ & 126 & $53.9 \%$ \\
Place of delivery (218) & \\
Hospital & 193 & $88.5 \%$ \\
Health centre & 18 & $8.3 \%$ \\
Home/TBA & 7 & $3.2 \%$ \\
Baby's & birth & \\
weight (237) & & \\
$<2.5 \mathrm{kgs}$ & 24 & $10.1 \%$ \\
$\geq 2.5 \mathrm{kgs}$ & 213 & $89.9 \%$ \\
Baby's gender (217) & & \\
Male & 143 & $65.9 \%$ \\
Female & 74 & $34 . \%$ \\
Gestational age at birth (247) & \\
Term & 230 & $93.1 \%$ \\
Preterm & 17 & $6.9 \%$ \\
ABO incompatibility (149) & \\
Compatible & 78 & $52.4 \%$ \\
Incompatible & 71 & $47.7 \%$ \\
Rhesus incompatibility (149) & \\
Incompatible & 6 & $96.0 \%$ \\
Compatible & 143 & \\
\hline
\end{tabular}

*Where $\mathrm{n}$ is $\leq 242$ due to missing data for the variable

Prevalence of neonatal hyperbilirubinaemia

During the study period, the prevalence of neonatal hyperbilirubinaemia in the baby unit was $7.75 \%$. On admission, severe hyperbilirubinaemia (defined as babies that required an exchange transfusion according to the AAP guidelines) was in 30/242 (12.4\%) of the babies and significant hyperbilirubinaemia (defined as both the babies that required intensive phototherapy and those that required exchange transfusion according to the AAP guidelines) was in 55/242 (22.7\%) of the babies. One hundred and eighty seven babies (77.3\%) did not require treatment for hyperbilirubinaemia (according to the AAP guidelines).

Factors associated with significant hyperbilribuinaemia We sought to find out if any factors were associated with significant hyperbilirubinaemia. No factors were found to be associated as shown in Table 2. 
Table 2: Factors associated with significant hyperbilirubinaemia

\begin{tabular}{|c|c|c|c|c|c|c|}
\hline Variable (n)* & $\begin{array}{l}\text { Total in } \\
\text { category }\end{array}$ & $\begin{array}{l}\text { Number (\%) } \\
\text { with Significant } \\
\text { hyperbilirubinea } \\
\text { mia }\end{array}$ & $\begin{array}{l}\text { COR }(95 \% \\
\text { CI) }\end{array}$ & P value & $\begin{array}{l}\text { AOR }(95 \% \\
\text { CI) }\end{array}$ & $\begin{array}{l}P \\
\text { value }\end{array}$ \\
\hline \multicolumn{7}{|c|}{ Maternal age (216) } \\
\hline $16-24$ years & 63 & $11(17.5)$ & - & 0.3700 & - & 0.118 \\
\hline$=25$ years & 153 & $35(22.9)$ & $\begin{array}{l}1.40(0.66 \\
2.97)\end{array}$ & & $\begin{array}{l}7.14(0.61, \\
84.06)\end{array}$ & \\
\hline \multicolumn{7}{|l|}{ Parity (227) } \\
\hline 1 & 103 & $20(19.4)$ & - & 0.3139 & - & 0.251 \\
\hline$=2$ & 124 & $31(24.8)$ & $\begin{array}{l}1.38(0.73 \\
2.61)\end{array}$ & & $\begin{array}{l}0.42(0.09 \\
1.85)\end{array}$ & \\
\hline \multicolumn{7}{|c|}{ Place of delivery (214) } \\
\hline Hospital & 189 & $40(21.2)$ & - & 0.2582 & - & 0.4534 \\
\hline Health centre & 18 & $6(33.3)$ & $\begin{array}{l}1.86(0.66 \\
5.27)\end{array}$ & & $\begin{array}{l}2.63(0.24, \\
29.26)\end{array}$ & \\
\hline Home & 7 & $3(42.9)$ & $\begin{array}{l}2.79(0.60, \\
12.99)\end{array}$ & & $\begin{array}{l}4.46(0.26 \\
75.83)\end{array}$ & \\
\hline \multicolumn{7}{|c|}{ Baby's birth weight (232) } \\
\hline$<2.5 \mathrm{kgs}$ & 24 & $6(25.0)$ & - & 0.8340 & - & 0.140 \\
\hline$=2.5 \mathrm{kgs}$ & 208 & $48(23.1)$ & $\begin{array}{l}0.90(0.34, \\
2.39)\end{array}$ & & $\begin{array}{l}0.23(0.03, \\
1.62)\end{array}$ & \\
\hline \multicolumn{7}{|c|}{ Baby's gender (209) } \\
\hline Male & 137 & $34(24.8)$ & - & 0.2596 & - & 0.526 \\
\hline Female & 72 & $13(18.1)$ & $\begin{array}{l}0.67(0.32, \\
1.36)\end{array}$ & & $\begin{array}{l}0.60(0.12, \\
2.93)\end{array}$ & \\
\hline \multicolumn{7}{|c|}{ ABO incompatibility (144) } \\
\hline Compatible & 75 & $17(22.7)$ & - & 0.0317 & - & 0.122 \\
\hline Incompatible & 69 & $27(39.1)$ & $\begin{array}{l}0.46(0.22, \\
0.94)\end{array}$ & & $\begin{array}{l}0.30(0.06, \\
1.39)\end{array}$ & \\
\hline \multicolumn{7}{|c|}{ Rhesus incompatibility (144) } \\
\hline Incompatible & 6 & $3(50.0)$ & - & & - & 0.202 \\
\hline Compatible & 138 & $41(29.7)$ & $\begin{array}{l}0.42(0.08, \\
2.18)\end{array}$ & 0.3100 & $\begin{array}{l}0.11(0.004, \\
3.20)\end{array}$ & \\
\hline
\end{tabular}

*Where $\mathrm{n}$ is less than 242 due to missing data for that variable

\section{Outcome of severe hyperbilirubinaemia}

Of the babies admitted with hyperbilirubinaemia, 235/242 (97\%) were discharged alive. Seven babies died, giving a mortality of $2.9 \%$. Six of the babies had severe hyperbilirubinaemia and one baby died due to severe anaemia. Of the 6 babies with severe hyperbilirubinaemia, 1 had rhesus incompatibility and 2 had ABO incompatibility. The case fatality rate for the babies with severe hyperbilirubinaemia was $20 \%(6 / 30)$. No preterm baby died. 


\section{Treatment given}

The babies that received phototherapy were $240 / 242(99.2 \%)$. Of these, 209/242 (86.4\%) babies received fluorescent light treatment while 12.8\% (31/242) received LED phototherapy light. The median number of days with LED phototherapy was 3days (IQR 1-5 days) whereas the median treatment with fluorescent phototherapy was 4 days (IQR 3-5 days).

Of the babies with severe hyperbilirubinaemia (30/242), exchange transfusion was carried out in $7 \%(17 / 242)$ while 13/242 received only phototherapy treatment. Case fatality was $38.5 \%(5 / 13)$ among the babies that received phototherapy treatment alone, and $11.8 \%$ among those who received an exchange transfusion.

Only 1 preterm baby received an exchange transfusion. Four babies had the procedure carried out twice.

Blood transfusions were carried out in 5 babies, 3 of whom had severe hyperbilirubinaemia.

\section{Discussion}

This study sought to find out the prevalence, treatment outcome and factors associated with neonatal hyperbilirubinaemia at St Francis hospital, Nsambya.

The prevalence of severe hyperbilirubinaemia is high but similar to that in an Egyptian study where 14.6\% of the babies had extreme hyperbilirubinaemia with cut off value of $\geq 513 \mu \mathrm{mol} / \mathrm{L}(28.5 \mathrm{mg} / \mathrm{dl})^{15}$. This reflects the already known high burden of disease in LMICs ${ }^{5}$. When stratified and compared to the AAP guidelines, approximately two thirds of the babies did not require treatment for hyperbilirubinaemia since their TSB levels were below the phototherapy line. This is a large number of patients however, many of these babies presented with otherymptoms such as fever and poor feeding with probably sepsis complicating the presentation of hyperbilirubinaemia.

No factors were found to be associated with significant hyperbilirubinaemia. Literature shows a diverse number of factors associated with neonatal hyperbilirubinaemia ${ }^{16}$. A recent study in Uganda showed a10.6\% prevalence of G6PD deficiency in neonates ${ }^{17}$. This particular condition was not sought for in our babies and could have been a major cause of neonatal hyperbilirubinaemia.

In our study, only about half of the babies with severe hyperbilirubinaemia $(17 / 30)$ had an exchange transfu- sion. The exchange transfusion rate is low for a LMIC but is similar to that seen in Bangladesh. It is much lower than that seen in an Iranian hospital where it was $35.5 \%{ }^{18}$ and in Nigeria where it ranged from $0-35 \% 19$. Obtaining fresh blood for an exchange transfusion is challenging as has been noted in other $\mathrm{LMICs}^{20}$. In our study, 4 babies that died, required an exchange transfusion but did not receive it.

Mortality in this study is high, but comparable to other LMICs $^{15,21}$. However, it is much lower than a number of Nigerian studies ${ }^{19,22}$.

The case fatality rate is extremely high, but similar to a longitudinal study carried out in Nigeria where it was $14.5 \%{ }^{23}$. Again we see that late presentation of the patients and unavailability of resources for appropriate management may be responsible for this mortality. Among the babies with severe hyperbilirubineamia, the case fatality was 3 times higher in those who received phototherapy alone compared to those who received an exchange transfusion. Phototherapy is a recognized and acceptable form of managing hyperbilirubinaemia and has been shown to reduce exchange transfusion rates in many settings ${ }^{24}$. In our study, however, most of the phototherapy units were substandard. Olusanya et al note that the overcrowding of phototherapy lights and their use by untrained staff compromises their effectiveness in many $\mathrm{LMICs}^{25}$. They recommend the use of low-cost phototherapy units that are regularly monitored and properly maintained in order to reduce the exchange transfusion rates in this region which have their own complications.

\section{Strengths and limitations}

This study, being among the first of it's kind in East Africa, gives us a quick look at the magnitude of the problem in this region

The retrospective type of study design did not permit us to identify factors associated with significant hyperbilirubinaemia since there was a lot of missing relevant data such as gender of the babies, blood groups of the mother and babies.

Severe hyperbilirubinaemia could have been underestimated since the risk factors for severe disease.e.g. sepsis, birth asphyxia, e.t.c, were not put into consideration and thus graphs for low and medium risk were used rather than the high risk graph, of the AAP guidelines 


\section{Conclusion and recommendations}

Appropriate, relevant guidelines for the management of neonatal hyperbilirubinaemia need to be established to prevent unnecessary admissions and ensure safe and timely treatment is given to those who require it.

Exchange transfusion is a life-saving procedure for babies coming late with neonatal hyperbilirubinaemia and availability of fresh blood should be prioritized in this age group.

Larger longitudinal studies are required to establish factors associated with neonatal hyperbilirubinaemia in this region.

\section{Competing interests}

The authors state no competing interests.

\section{References}

1. Wang H, Bhutta ZA, Coates MM, Coggeshall M, Dandona L, Diallo K, et al. Global, regional, national, and selected subnational levels of stillbirths, neonatal, infant, and under-5 mortality, 1980-2015: a systematic analysis for the Global Burden of Disease Study 2015. The Lancet. 2016;388(10053):1725.

2. Liu L, Oza S, Hogan D, Chu Y, Perin J, Zhu J, et al. Global, regional, and national causes of under- 5 mortality in 2000-15: an updated systematic analysis with implications for the Sustainable Development Goals. The Lancet. 2017;388(10063):3027-35.

3. Olusanya BO, Teeple S, Kassebaum NJ. The contribution of neonatal jaundice to global child mortality: findings from the GBD 2016 Study. Pediatrics. 2018;141(2):e20171471.

4. Bhutani VK, Zipursky A, Blencowe H, Khanna R, Sgro M, Ebbesen F, et al. Neonatal hyperbilirubinemia and Rhesus disease of the newborn: incidence and impairment estimates for 2010 at regional and global levels. Pediatric Research. 2013;74(Suppl 1):86.

5. Greco C, Arnolda G, Boo N-Y, Iskander IF, Okolo AA, Rohsiswatmo R, et al. Neonatal jaundice in Lowand middle-income countries: lessons and future directions from the 2015 don ostrow trieste yellow retreat. Neonatology. 2016;110(3):172-80.

6. Newman TB, Xiong B, Gonzales VM, Escobar GJ. Prediction and prevention of extreme neonatal hyperbilirubinemia in a mature health maintenance organization. Archives of Pediatrics \& Adolescent Medicine. 2000;154(11):1140-7.

7. Ogunlesi TA, Ogunfowora OB. Predictors of acute bilirubin encephalopathy among Nigerian term babies with moderate-to-severe hyperbilirubinaemia. Journal of Tropical Pediatrics. 2010;57(2):80-6.

8. Tiwari P, Bhutada A, Agarwal R, Basu S, Raman R, Kumar A. UGT1A1 gene variants and clinical risk factors modulate hyperbilirubinemia risk in newborns. Journal of Perinatology. 2014;34(2):120-4.

9. Slusher TM, Vreman HJ, McLaren DW, Lewison LJ, Brown AK, Stevenson DK. Glucose-6-phosphate dehydrogenase deficiency and carboxyhemoglobin concentrations associated with bilirubin-related morbidity and death in Nigerian infants. The Journal of Pediatrics. 1995;126(1):102-8.

10. Kalakheti B, Singh R, Bhatta N, Karki A, Baral N. Risk of neonatal hyperbilirubinemia in babies born to 'O'positive mothers: A prospective cohort study. Kathmandu University Medical Journal. 2009;7(1):11-5.

11. Vos G, Adhikari M, Coovadia H. A study of ABO incompatibility and neonatal jaundice in Black South African newborn infants. Transfusion. 1981;21(6):744-9.

12. Wambuzi L. Prevalence, associated factors and immediate outcome of neonatal jaundice in special care unit, Mulago Hospital. 2009.

13. Kish L. Sampling organizations and groups of unequal sizes. American Sociological Review. 1965:564-72.

14. Onyearugha C, Onyire B, Ugboma H. Neonatal jaundice: Prevalence and associated factors as seen in Federal medical centre Abakaliki, Southeast Nigeria. Journal of Clinical Medicine and Research. 2011;3(3):40-5.

15. Iskander I, Gamaleldin R, Kabbani M. Root causes for late presentation of severe neonatal hyperbilirubinaemia in Egypt. Eastern Mediterranean Health Journal. 2012;18(8).

16. Olusanya BO, Osibanjo FB, Slusher TM. Risk factors for severe neonatal hyperbilirubinemia in low and middle-income countries: a systematic review and meta-analysis. PLoS One. 2015;10(2):e0117229.

17. Stadem PS, Hilgers MV, Bengo D, Cusick SE, Ndidde S, Slusher TM, et al. Markers of oxidative stress in umbilical cord blood from G6PD deficient African newborns. PloS One. 2017;12(2):e0172980.

18. Najib KS, Saki F, Hemmati F, Inaloo S. Incidence, risk factors and causes of severe neonatal hyperbilirubinemia in the South of iran (fars province). Iranian Red Crescent Medical Journal. 2013;15(3):260.

19. Israel-Aina $Y$, Omoigberale A. Risk factors for neonatal jaundice in babies presenting at the University of Benin Teaching Hospital, Benin City. Nigerian Journal of Paediatrics. 2012;39(4):159-63.

20. Olusanya BO, Ogunlesi TA, Slusher TM. Why is 
kernicterus still a major cause of death and disability in low-income and middle-income countries? Archives of Disease in Childhood. 2014:archdischild-2013-305506. 21. Rasul CH, Hasan MA, Yasmin F. Outcome of neonatal hyperbilirubinemia in a tertiary care hospital in Bangladesh. The Malaysian Journal of Medical Sciences: MJMS. 2010;17(2):40.

22. Okposio M, Ighosewe O. Morbidity and mortality pattern among neonates admitted to the general paediatric ward of a secondary health care centre in the Niger delta region of Nigeria. Sri Lanka Journal of Child Health. 2016;45(2).
23. Osuorah CD, Ekwochi U, Asinobi IN. Clinical evaluation of severe neonatal Hyperbilirubinaemia in a resource-limited setting: a 4-year longitudinal study in south-East Nigeria. BMC Pediatrics. 2018;18(1):202.

24. Watchko J. Recent advances in the management of neonatal jaundice. Research and Reports in Neonatology. 2014:183-.

25. Olusanya BO, Ogunlesi TA, Kumar P, Boo N-Y, Iskander IF, de Almeida MFB, et al. Management of late-preterm and term infants with hyperbilirubinaemia in resource-constrained settings. BMC Pediatrics. 2015;15(1):39. 